\title{
Noninvasive Ventilation Therapy: Practical issues in the Domiciliary use
}

\author{
${ }^{1}$ Ravi Dosi, ${ }^{2}$ Priyanshu Jain, ${ }^{3}$ Arpit Jain, ${ }^{4}$ Satish Motiwale, ${ }^{5}$ Prakash Joshi
}

\begin{abstract}
Noninvasive ventilation (NIV) therapy has become the standard of care for home therapy of patients suffering from sleep apnea and chronic Type 2 respiratory failure. We did a retrospective study of a patient admitted with the exacerbation of these disease despite of being advised home NIV therapy. The study was performed in a tertiary care institute in the past 2 years.
\end{abstract}

A total of 186 patient of chronic respiratory failure were studied who were prescribed NIV, out of which 96 patients who adhered to NIV were followed, and reasons of readmission and practical issues were studied. All the patient admitted to respiratory and general intensive care unit (ICU) were included, who needed a stay of more than 5 days. Out of 96 patients, 30 patients are of severe sleep apnea, and 25 patients are of severe chronic obstructive pulmonary disease (COPD). The most common cause of such patients going into respiratory failure after use of NIV being recurrent infection and poor willingness to continue with NIV due to psychological and medical reasons. Commonly seen medical reasons were ulcer over the bridge of the nose; inability to sleep with a mask on and feeling of suffocation with the mask. Psychological reasons include depression symptoms and a feeling of loneliness. We recorded that patient with regular follow up; the active role played by younger family members and patient on nasal mask had better outcome results as compared to their medical counterparts.

Keywords: Compliance, Domiciliary use, NIV.

How to cite this article: Dosi R, Jain P, Jain A, Motiwale $S$, Joshi P. NIV Therapy: Practical issues in the Domiciliary use. Indian Sleep Med 2018;13(3):39-41.

Source of support: Nil

Conflict of interest: None

\section{INTRODUCTION}

Domiciliary NIV is an increasingly used intervention to curtail the detrimental effects of chronic respiratory failure (CRF) in individuals with a broad range of cardiorespiratory disorders. NIV therapy has become

\footnotetext{
${ }^{1}$ Assosciate Professor, ${ }^{2}$ 2nd Year MD Resident, ${ }^{3} 3$ rd Year MD Resident, ${ }^{4} \mathrm{HOD},{ }^{5}$ Consultant

1-5Department of Respiratory Diseases, SAMC and PGI, Indore, Madhya Pradesh, India

Corresponding Author: Priyanshu Jain, 2nd Year MD Resident, Department of Respiratory Diseases, SAMC and PGI, Indore, Madhya Pradesh, India, Email: jain.priyanshu14@gmail.com
}

the standard of care for home therapy of patients suffering from sleep apnea and chronic Type 2 respiratory failure. Progress in the provision, ease of application, and improved monitoring of the efficacy of NIV, which itself aims to address the abnormalities mentioned above, has simply been staggering over the last decade. The purpose of domiciliary NIV, in its essence, is to treat hypoventilation, control any associated symptoms in the patient of chronic respiratory failure. With the advent of modern technology in NIV, the quality of life of chronic respiratory disease patients (COPD, OSA, ILD, chest wall deformity, neuromuscular diseases) showed improvement in overall functional ability. ${ }^{1}$ In general, pressure and volume targeted ventilatory targets are used in chronic respiratory failure, both of which are efficacious when used for short-term but when it comes for long-term use different practical issues are faced by patients. ${ }^{2-4}$ Requirement and practical implementation may vary with different patient conditions. ${ }^{5-8}$ There are many challenges with the long-term use of NIV include eye irritation, nasal and oral dryness, aerophagia and gastrointestinal distention, vomiting, pneumothorax, pneumonia, air leak, ulcer over the bridge of a nose, dysynchrony. ${ }^{9,10}$ Different studies speculate different parameters superior or inferior in NIV may it be pressure support ventilation or volume support ventilation. However, pressure and volume ventilation were found equivalent regarding improvement in respiratory physiology and the consequent changes in health status. ${ }^{11}$ NIV masks are equal culprit in increasing unadherence of NIV in patients during long-term use.

\section{MATERIALS AND METHODS}

We did a retrospective study of 186 patients admitted with the exacerbation of these diseases despite being advised home NIV therapy. The study was done in the Department of Respiratory medicine, Sri Aurobindo Institute of Medical Sciences in the past 2 years from 2016-2018. Out of total patients, 96 patients were included in this study, 52 were males and 44 were females (Fig. 1). Patients admitted to the respiratory ICU, and general ICU were included, who needed a stay of more than 3 days and needed invasive ventilatory support. Exclusion criteria included patients not advised domiciliary NIV therapy. All the patients with established clinical diagnosis and advised domiciliary NIV therapy, when admitted in our hospital with acute exacerbation, a retrospective study was done to know 


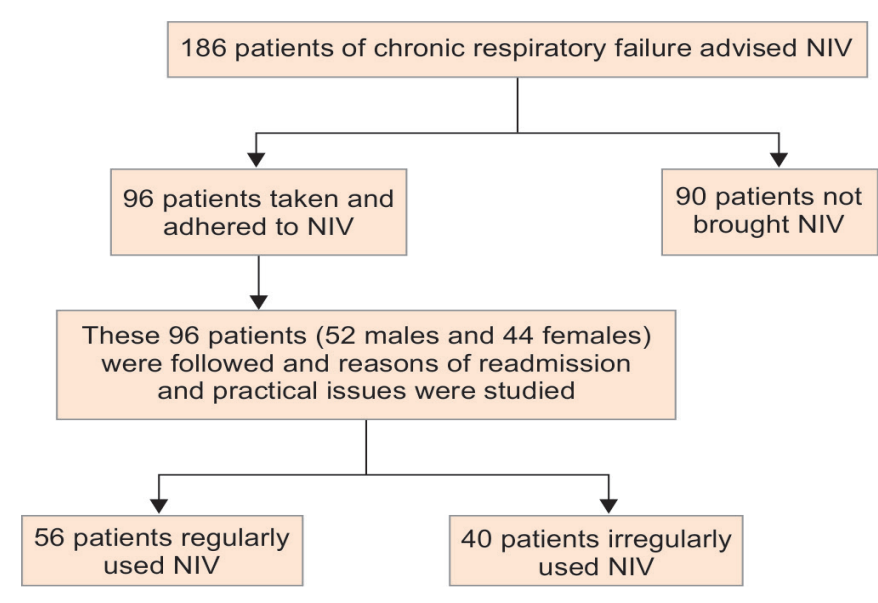

Fig. 1: Showing the number of included patients

the cause of exacerbations, detailed history and complete clinical workup of the patients was done and the reason of in adherent with NIV noted.

\section{STATISTICAL ANALYSIS}

Statistical analysis was performed using statistical package for the social sciences (SPSS) version 17.0 (SPSS Inc, Chicago, Illinois, United States of America). Data are presented as mean values $\pm \mathrm{SD}$. Analysis of variance (ANOVA) performed comparisons between groups with Bonferroni's multiple comparison test after confirming normality of the data by the D'Agostino-Pearson test. A p-value of less than 0.05 was considered significant.

\section{RESULT}

A total of 96 subjects were included in the study. Anthropometric characteristics of all patients are summarized in Table 1. Maximum patients were those with severe sleep apnea and severe COPD with cor-pulmonale. Out of 96 patients, 30 patients are of severe sleep apnea, and 25 patients are of severe COPD (Fig. 2).

Table 1: Anthropometric data

\begin{tabular}{lll}
\hline Parameter & Male & Female \\
\hline Number & 52 & 44 \\
Age years & $48(+/-15)$ & $45(+/-9)$ \\
Height $(\mathrm{cm})$ & $166(+/-9)$ & $155(+/-5)$ \\
Weight $(\mathrm{kg})$ & $84(+/-18)$ & $78(+/-12)$ \\
Smokers & 11 & 2 \\
\hline
\end{tabular}

The most common cause of such patients going into respiratory failure was:

\section{Recurrent infection}

Poor willingness to continue with NIV due to psychological and medical reasons and some family issues (Table 2).

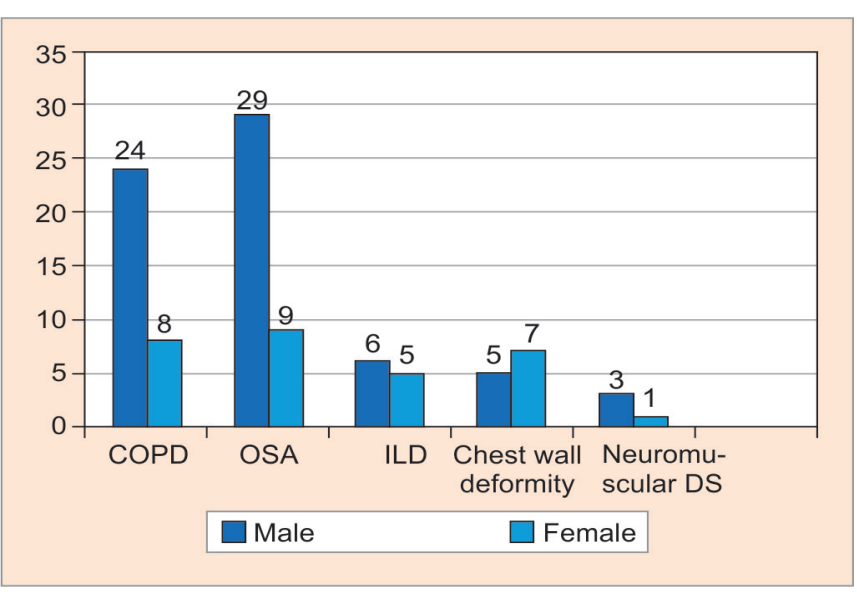

Fig. 2: Diseases in which NIV given

Table 2: Causes of exacerbation

\begin{tabular}{lll}
\hline Cause & No. of patient & $\%$ \\
\hline Recurrent infection & 35 & 38.8 \\
Medical reasons & 27 & 28.1 \\
Psychological reasons & 20 & 20.08 \\
Intolerable & 14 & 14.58 \\
Poor secretion expulsion & 16 & 16.6 \\
Family issues & 29 & 30.2 \\
\hline
\end{tabular}

Commonly seen medical reasons were ulcer over the bridge of the nose; inability to sleep with a mask on and feeling of suffocation with the mask. Psychological reasons include depression symptoms and feeling of loneliness (Fig. 3).

\section{DISCUSSION}

Appropriate strategies to ensure adequacy of ventilation and respiratory support is necessary. During sleep itself, and respiratory events can be attributed to either sleeprelated physiological events or due to events as a consequence of the inherent use of NIV in and of itself. ${ }^{12}$ The latter can be precipitated by infected face masks, interface leaks, instability of the upper airway, and any residual obstructive events, with or without glottis closure, or patient-ventilator asynchrony.

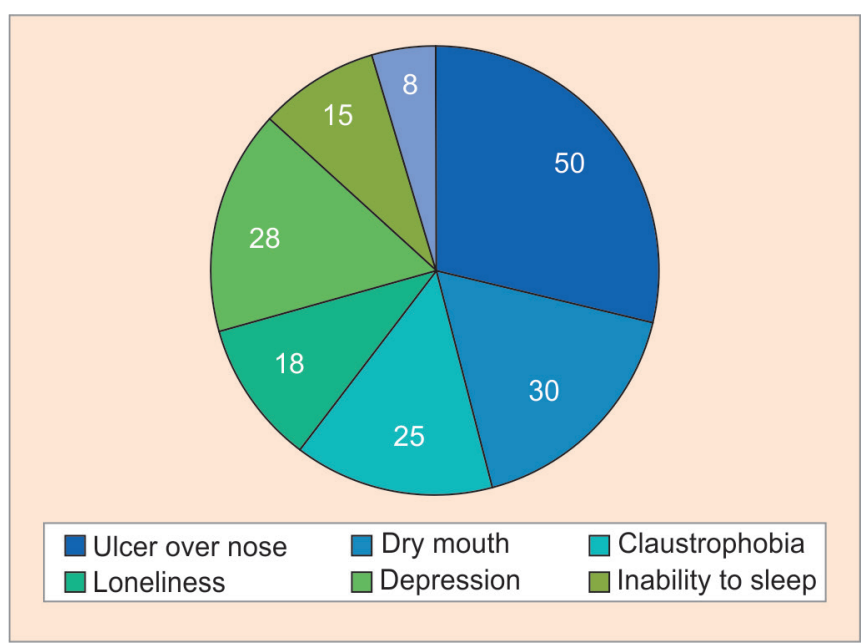

Fig. 3: Problems faced by patients 
Patient ventilatory asynchrony can be manifested as problems with triggering of the ventilator. This can include ineffective triggering, double triggering, auto-triggering (usually caused by leaks causing the EPA level to fall below the trigger threshold), and/or with timing out of phase. Adjusting trigger and cycling sensitivity, inspiratory time limits and rise times, and time in inspiratory pressure assists as a percentage of the respiratory cycle all serve to optimize efficacy and minimize patient-ventilator asynchrony. ${ }^{13,14}$ Some more recent ventilators propose automated complex trigger algorithms by which the actual flow-time waveform is used as a means to identify the appropriate time to trigger the ventilator.

Options for monitoring purposes can include oxygen desaturation or an elevation in transcutaneous carbon dioxide levels. More modern home ventilators are designed to be capable of detecting and recording a diverse range of parameters over several months and so providing relevant information to the clinician. These include the establishing the amount of leak, if any, a degree of compliance, overall use in hours per night, tidal volumes achieved, and for some ventilators, an estimate of persistent respiratory compromise in the form of an apnea-hypopnea index.

Different ty pes of NIV mask interface are:

- Mouthpiece: Placed between the patients lips and held in place by lip-seal

- Nasal mask: Covers the nose but not the mouth

- Nasal pillows: Plugs inserted into the nostrils

- Oronasal: Covers the nose and mouth

- Full-face: Covers the mouth, nose, and eyes

- Helmet: Covers the whole head and all or part of the neck; No contact with the face or head.

In resource-limited countries like India, NIV is used often in homes without adequate training. A recent Indian questionnaire-based study carried out to analyze the practice of NIV revealed that around $72 \%$ of physicians (intensivists, anesthetists, respiratory physicians) used NIV in their practice. Lack of adequate counseling was common reason for the improper use of NIV. ${ }^{15}$

\section{CONCLUSION}

We recorded that patient with regular follow-up, and active role played by younger family members and patient on nasal mask had better outcome results as compared to their medical counterparts. Proper application and cleaning of masks and minimizing air leaks is one of the most vital factors in improve patient compliance and ensuring improved ventilation. With regular counseling of patient and family member, domiciliary use of NIV in patients with chronic respiratory diseases can lead to mark improvement in their quality of life with long-term cost benefits. NIV is apparently a major tool in the armamentarium of pulmonologist and intensivists.

\section{REFERENCES}

1. Renston JP, DiMarco AF, Supinski GS, et al. Respiratory muscle rest using nasal BiPAP ventilation in patients with stable severe COPD. Chest 1994:105: 1053-1060.

2. Restrick LJ, Fox NC, Braid G, Ward EM, Paul EA, et al. Comparison of nasal pressure support ventilation with nasal intermittent positive pressure ventilation in patients with nocturnal hypoventilation. Eur Respir J 1993: 6: 364-370.

3. Chadda K, Clair B, Orlikowski D, Macadoux G, Raphael JC, et al. Pressure support versus assisted controlled noninvasive ventilation in neuromuscular disease. Neurocrit Care 2004:1:429-434.

4. Muñoz X, Crespo A, Marti S, Torres F, Ferrer J, et al. Comparative study of two different modes of noninvasive home mechanical ventilation in chronic respiratory failure. Respir Med 2006:100: 673-681.

5. Windisch W, Storre JH, Sorichter S, Virchow JC Jr, et al. Comparison of volume- and pressure-limited NPPV at night: a prospective randomized crossover trial. Respir Med 2005:99:52-59.

6. Vitacca M, Rubini F, Foglio K, Scalvini S, Nava S, et al. Non-invasive modalities of positive pressure ventilation improve the outcome of acute exacerbations in COLD patients. Intensive Care Med 1993:19: 450-455.

7. Hess DR, et al. The evidence for noninvasive positive-pressure ventilation in the care of patients in acute respiratory failure: a systematic review of the literature. Respir Care 2004:49: 810-829.

8. Pinto A, Almeida JP, Pinto S, Pereira J, Oliveira AG, et al. Home telemonitoring of non-invasive ventilation decreases healthcare utilisation in a prospective controlled trial of patients with amyotrophic lateral sclerosis. J Neurol Neurosurg Psychiatry 2010:81: 1238-1242.

9. Carrillo A, Ferrer M, Gonzalez-Diaz G, Lopez-Martinez A, Llamas $\mathrm{N}$, et al. Noninvasive ventilation in acute hypercapnic respiratory failure caused by obesity hypoventilation syndrome and chronic obstructive pulmonary disease.Am J RespirCrit Care Med 2012:186: 1279-1285.

10. Carron M, Freo U, BaHammam AS, Dellweg D, Guarracino F, et al. Complications of non-invasive ventilation techniques: a comprehensive qualitative review of randomized trials. Br J Anaesth 2013:110: 896-914.

11. Tuggey JM, Elliott MW. Randomised crossover study of pressure and volume non-invasive ventilation in chest wall deformity. Thorax 2005:60: 859-864.

12. Henke KG, Badr MS, Skatrud JB, Dempsey JA, et al. Load compensation and respiratory muscle function during sleep. J Appl Physiol (1985) 1992:72: 1221-1234.

13. Hess DR, et al. Patient-ventilator interaction during noninvasive ventilation. Respir Care 2011:56: 153-165.

14. Berry RB, Chediak A, Brown LK, Finder J, Gozal D, et al. Best clinical practices for the sleep center adjustment of noninvasive positive pressure ventilation (NPPV) in stable chronic alveolar hypoventilation syndromes. J Clin Sleep Med 2010:6: 491-509.

15. Chawla R, Sidhu US, Kumar V, Nagarkar S, Brochard L, et al. Noninvasive ventilation: a survey of practice patterns of itsuse in India. Indian J Crit Care Med 2008;12:163-169. 